\title{
PERANCANGAN TATA LETAK FASILITAS PRODUKSI PEYEK
}

\author{
Yaning Tri Hapsari ${ }^{1}$, Kurniawanti ${ }^{2}$ \\ ${ }^{1,2}$ Program Studi Teknik Industri, Fakultas Teknik, Universitas PGRI Yogyakarta \\ E-mail: yaning.yth@upy.ac.id
}

\begin{abstract}
The purpose of this service activity is to make the design proposals for production facilities in Peyek Ayu Bu Mul's MSMEs that are still less orderly, which causes a less effective movement of labor and raw materials (not needed). The proposed layout of production facilities is expected to facilitate production activities and eliminate unnecessary labor or raw material movements. Service begins with observation to find out the way and production flow of the project. Observation of the location of the production site needs to be done to find out the initial layout of the production site. The next step is to create an ARC (Activity Relationship Chart). This diagram is used to determine the closeness relationship and the reason for the proximity of each department/unit/space in the production location. The use of production flow analysis and ARC diagrams resulted in the proposed layout of production facilities at Peyek Ayu Bu Mul. The results of community service activities at MSME Peyek Ayu Bu Mul are MSME owners Peyek Ayu Bu Mul understands the importance of the layout of production facilities for the smooth production. MSME Peyek Aуи Bu Mul was interested in implementing the proposed layout of production facilities that had been made because it could improve the performance of the production. This service concluded that the design of the production facility layout by considering the production flow and production layout can help smooth production.
\end{abstract}

Keywords: peyek, production facility layout, ARC (Activity Relationship Chart)

\begin{abstract}
Abstrak. Tujuan pengabdian ini adalah membuat usulan rancangan tata letak fasillitas produksi di UMKM Peyek Ayu Bu Mul yang masih kurang teratur sehingga menyebabkan pergerakan tenaga kerja dan bahan baku yang kurang efektif (tidak diperlukan). Usulan rancangan tata letak fasilitas produksi ini diharapkan dapat memperlancar kegiatan produksi dan menghapus gerakan tenaga kerja atau bahan baku yang tidak diperlukan. Pengabdian dimulai dengan observasi untuk mengetahui cara dan aliran produksi peyek. Selain itu, observasi lokasi produksi peyek perlu dilakukan untuk mengetahui layout awal tempat produksi. Langkah selanjutnya yaitu dengan membuat ARC (Activity Relationship Chart). Diagram ini digunakan untuk mengetahui hubungan kedekatan dan alasan kedekatan setiap departemen/unit/ruang dalam lokasi produksi. Penggunaan analisis aliran produksi dan diagram ARC menghasilkan usulan rancangan tata letak fasilitas produksi di UMKM Peyek Ayu Bu Mul. Hasil dari kegiatan pengabdian masyarakat di UMKM Peyek Ayu Bu Mul adalah pemilik UMKM Peyek Ayu Bu Mul lebih memahami pentingnya tata letak fasilitas produksi untuk kelancaran produksi peyek. Selain itu, UMKM Peyek Ayu Bu Mul tertarik untuk menerapkan usulan tata letak fasilitas produksi yang dibuat oleh pengabdi karena dapat meningkatkan kinerja dari produksi peyek. Kesimpulan dari pengabdian ini adalah bahwa perancangan tata letak fasilitas produksi dengan mempertimbangkan aliran produksi dan tata letak produksi dapat membantu kelancaran produksi.
\end{abstract}

Kata kunci: peyek, tata letak faslitas produksi, ARC (Activity Relationship Chart)

\section{PENDAHULUAN}

UMKM yang bergerak di bidang makanan saat ini semakin banyak bermunculan. Makanan yang inovatif banyak menarik konsumen, seperti bakpia dengan berbagai macam rasa, bakso dengan bermacam isian, dan lain-lain. Namun, makanan tradisional pun masih menarik bagi konsumen, salah satunya yaitu peyek. Peyek merupakan sejenis keripik dengan berbagai rasa, seperti peyek kacang, peyek teri, dan peyek kedelai. Peyek banyak digemari masyarakat sebagai camilan karea rasanya yang gurih.

Salah satu usaha peyek yang terdapat di Yogyakarta yaitu Peyek Ayu Bu Mul. Peyek Ayu $\mathrm{Bu}$ Mul sudah berjalan kurang lebih 9 tahun dan sudah menyuplai ke beberapa hotel di Yogyakarta. Gambar 1 merupakan hasil produksi peyek di Peyek Ayu Bu Mul dan kegiatan produksi peyek di Peyek Ayu Bu Mul dapat dilihat pada Gambar 2. 


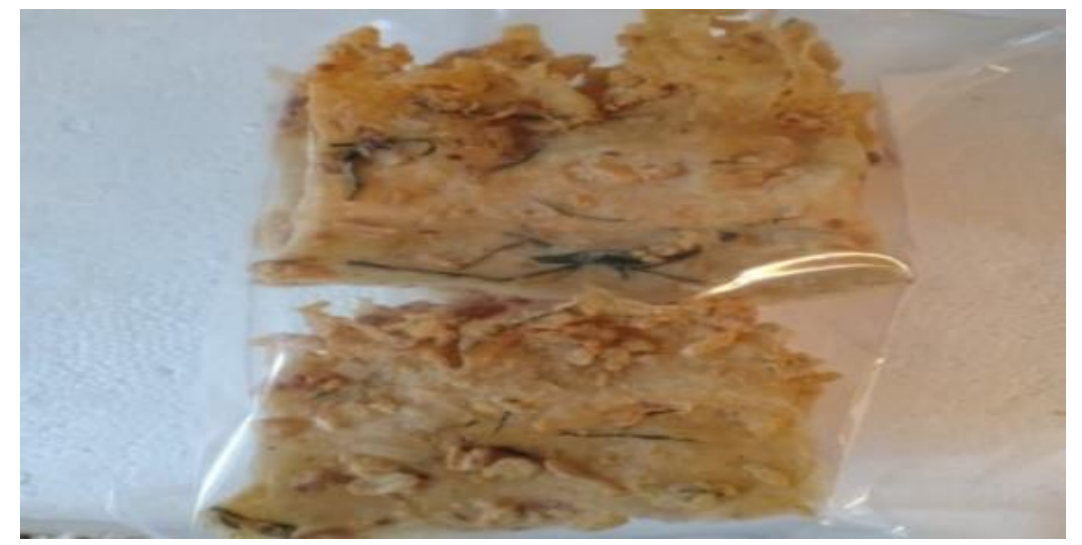

Gambar 1. Peyek

Produksi peyek yang berkualitas dalam rasa dan tekstur tidak hanya didukung dengan bahan baku yang berkualitas saja, tetapi juga perlu didukung dengan tata letak fasilitas produksi yang baik. Perancangan tata letak fasilitas bertujuan untuk menunjang kelancaran proses produksi, mencegah kecelakaan kerja dan menghapus gerakan tenaga kerja atau bahan baku yang tidak diperlukan. Perancangan fasilitas poduksi merupakan salah satu faktor yang sangat berpengaruh pada kinerja suatu perusahaan seperti yang dikemukakan oleh Sofyan dan Syarifuddin (2015). Selain itu menurut Morena dan Siska (2011) tujuan perancangan tata letak fasilitas yaitu untuk menentukan bagaimana koordinasi dari setiap fasilitas produksi diatur sedemikian rupa sehingga mampu menunjang upaya pencapaian efisiensi dan efektifitas operasi kegiatan produksi. Perancangan tata letak fasilitas juga dapat meningkatkan keselamatan kerja (Wang dkk, 2018).

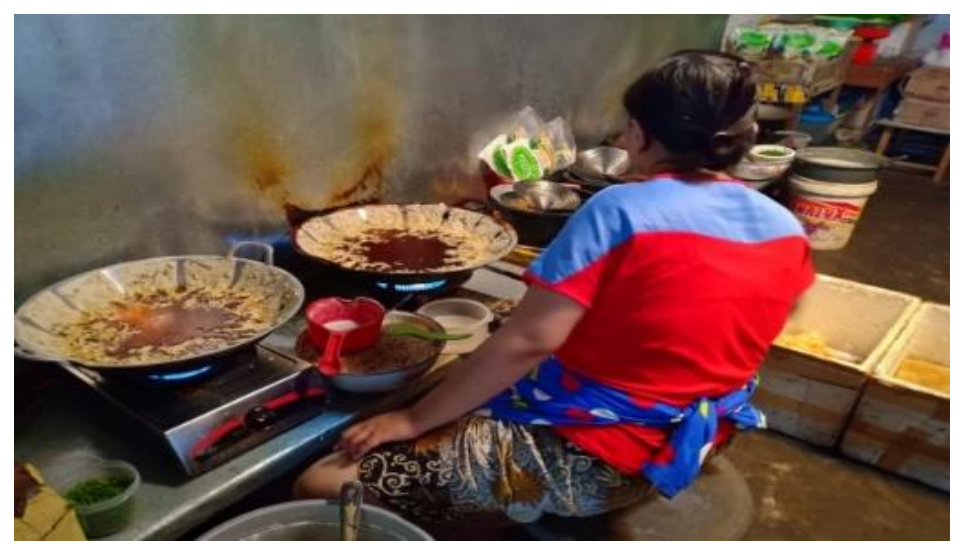

Gambar 2. Kegiatan Produksi Peyek

Selama pengamatan di lokasi produksi, tata letak fasilitas produksi di Peyek Ayu Bu Mul masih kurang teratur sehingga menyebabkan pergerakan tenaga kerja dan bahan baku yang kurang efektif (tidak diperlukan). Berdasarkan masalah yang dihadapi UMKM Peyek Ayu Bu Mul tersebut, maka pengabdi bertujuan untuk membuat usulan rancangan tata letak fasillitas produksi. Usulan rancangan tata letak fasilitas produksi ini diharapkan dapat memperlancar kegiatan produksi dan menghapus gerakan tenaga kerja atau bahan baku yang tidak diperlukan. Luaran dari pengabdian ini adalah usulan rancangan tata letak fasilitas produksi. 


\section{METODE}

Kegiatan pengabdian ini dimulai dari bulan Januari sampai bulan Juni 2019 dan bertempat di salah satu UMKM di Yogyakarta yaitu Peyek Ayu Bu Mul. Pengabdian dimulai dengan mengetahui cara dan aliran produksi peyek. Untuk mengetahui cara dan aliran produksi peyek maka pengabdi melakukan wawancara dengan pemilik usaha. Observasi lokasi produksi peyek perlu dilakukan untuk mengetahui layout awal tempat produksi. Langkah selanjutnya yaitu dengan membuat ARC (Activity Relationship Chart). Diagram ini digunakan untuk mengetahui hubungan kedekatan dan alasan kedekatan setiap departemen/unit dalam lokasi produksi. Gambar 3 menunjukkan langkah kegiatan yang digunakan dalam pengabdian ini. Gambar 4 menunjukkan cara produksi peyek yang di mulai dari menyiapkan bahan dan bumbu untuk dijadikan adonan, menggoreng, meniriskan, mengemas, dan menyimpan. Aliran produksi peyek yang ditunjukkan dalam Gambar 5.

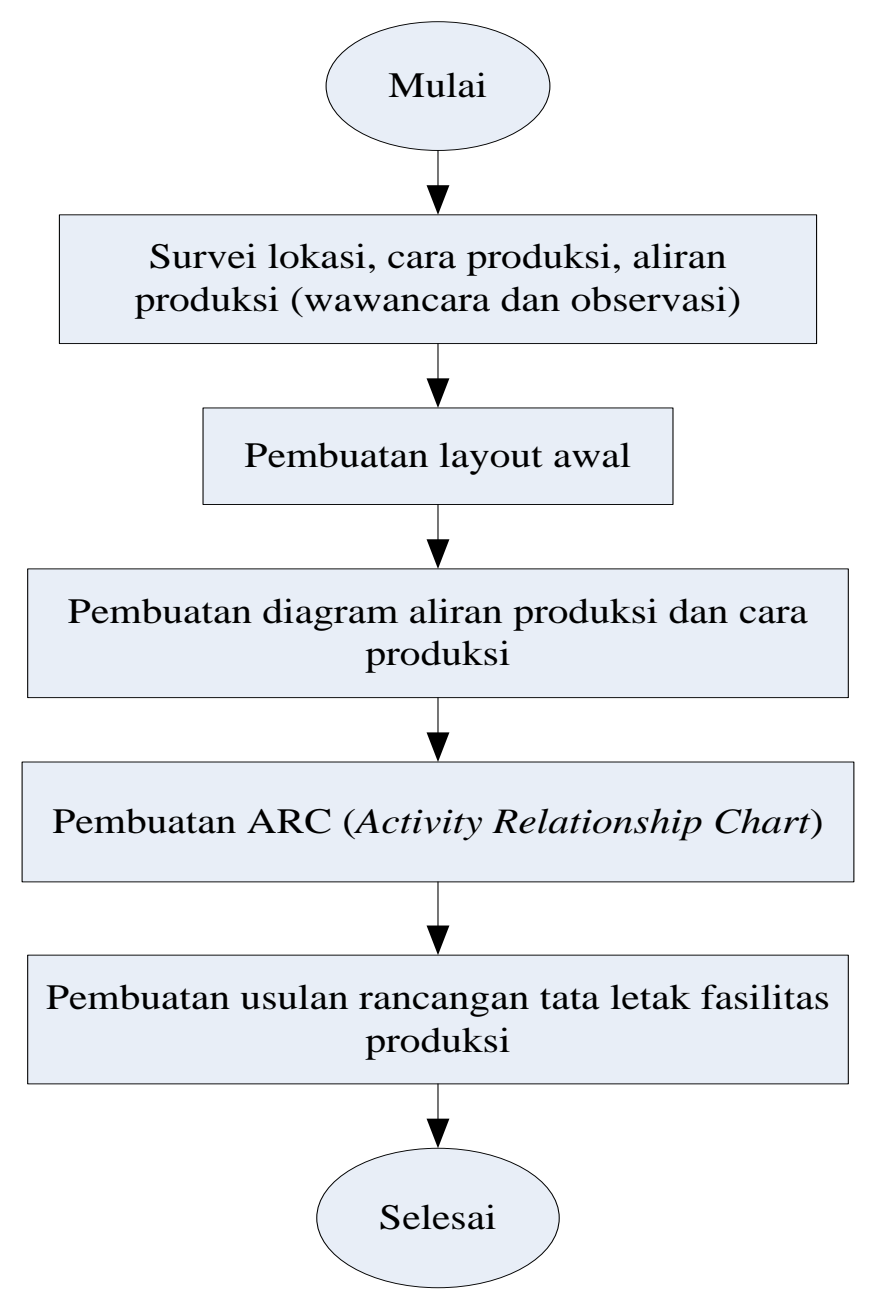

Gambar 3. Diagram Alir Kegiatan Pengabdian 


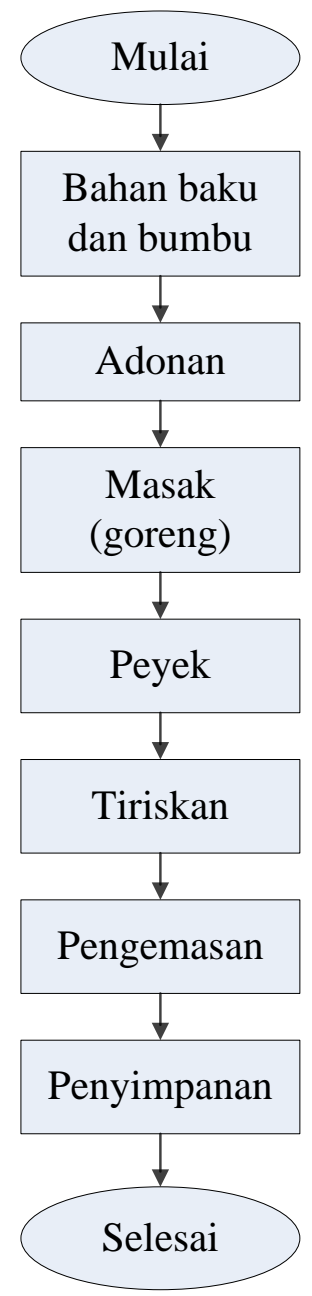

Gambar 4. Diagram Alir Proses Produksi Peyek

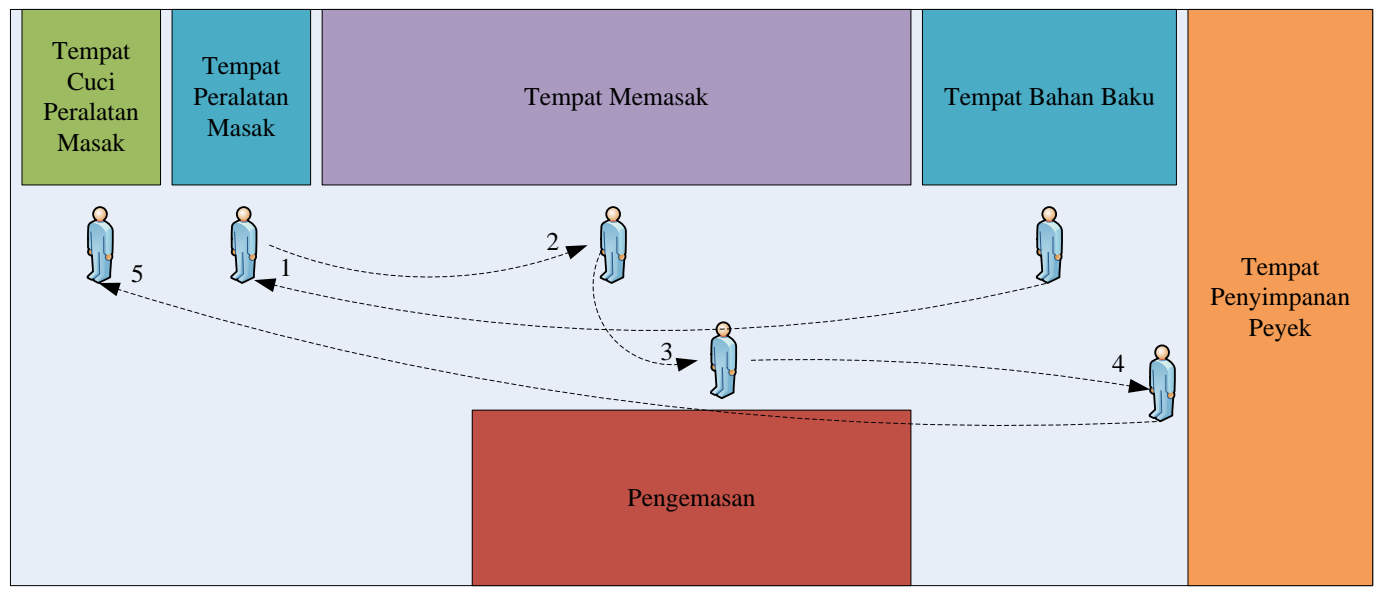

Gambar 5. Layout Aliran Proses Produksi Peyek 


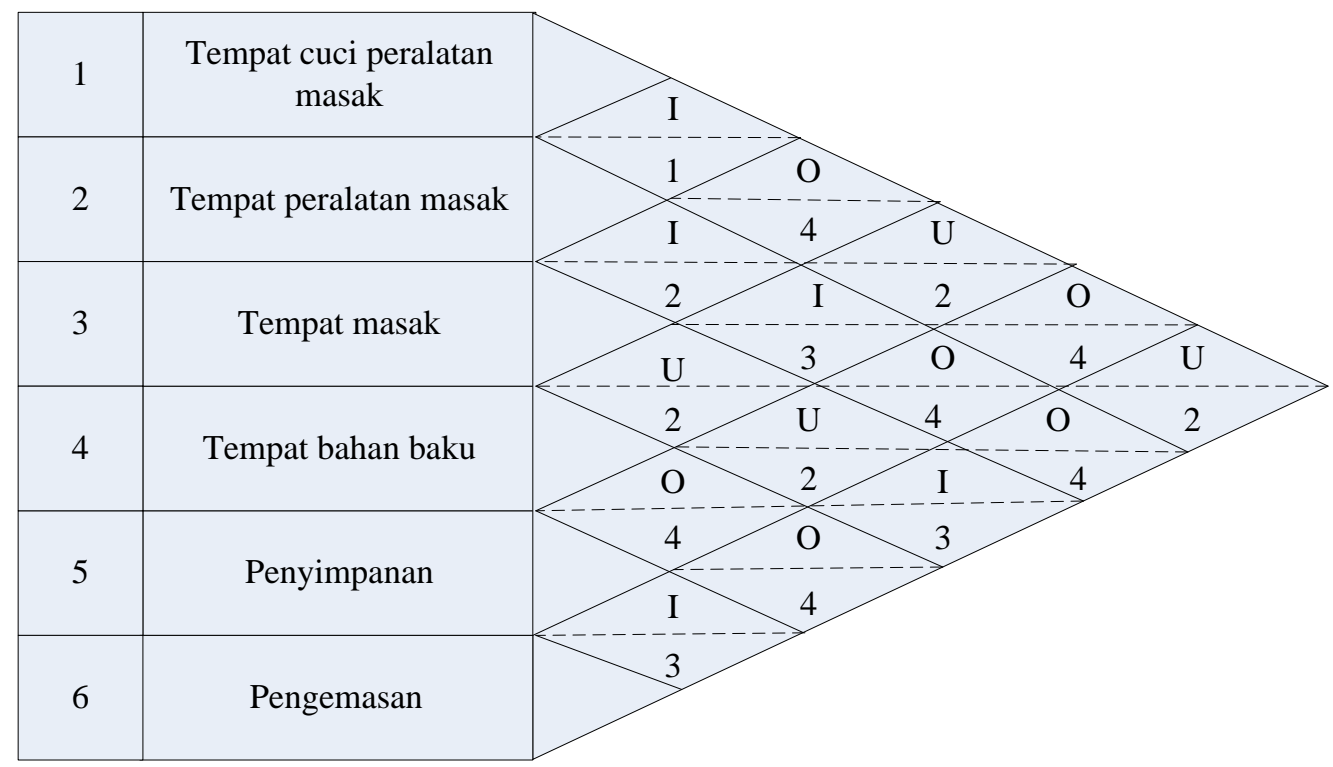

Gambar 6. ARC (Activity Relationship Chart) Peyek Ayu Bu Mul

Derajat hubungan dan alasan kedekatan ruangan dijelaskan pada Tabel 1 dan Tabel 2.

Tabel 1. Derajat Hubungan Ruangan Derajat Hubungan

\begin{tabular}{cl}
\hline A & Mutlak perlu berdekatan \\
\hline $\mathrm{E}$ & Sangat penting berdekatan \\
\hline $\mathrm{I}$ & Penting berdekatan \\
\hline $\mathrm{O}$ & Tidak jadi soal/biasa \\
\hline $\mathrm{U}$ & Tidak penting \\
\hline $\mathrm{X}$ & Tidak dikehendaki berdekatan
\end{tabular}

Tabel 2. Alasan Kedekatan Ruangan

\begin{tabular}{cl}
\hline Kode & \multicolumn{1}{c}{ Alasan } \\
\hline 1 & Kemudahan \\
\hline 2 & Merusak bahan \\
\hline 3 & Urutan aliran kerja \\
\hline 4 & Tidak berkepentingan
\end{tabular}

\section{HASIL DAN PEMBAHASAN}

Berdasarkan aliran produksi dan ARC, pengabdi mengusulkan rancangan ulang tata letak fasilitas produksi peyek seperti pada Gambar 8. Tempat cuci peralatan memasak, tempat peralatan memasak, dan tempat memasak tidak perlu diubah tata letaknya karena sudah sesuai dengan aliran produksi. Tempat penyimpanan peyek dan pengemasan dibuat berdekatan supaya peyek yang sudah dikemas dapat segera disimpan di tempat penyimpanan dan mengurangi jarak tempuh dari pengemasan ke tempat penyimpanan. 


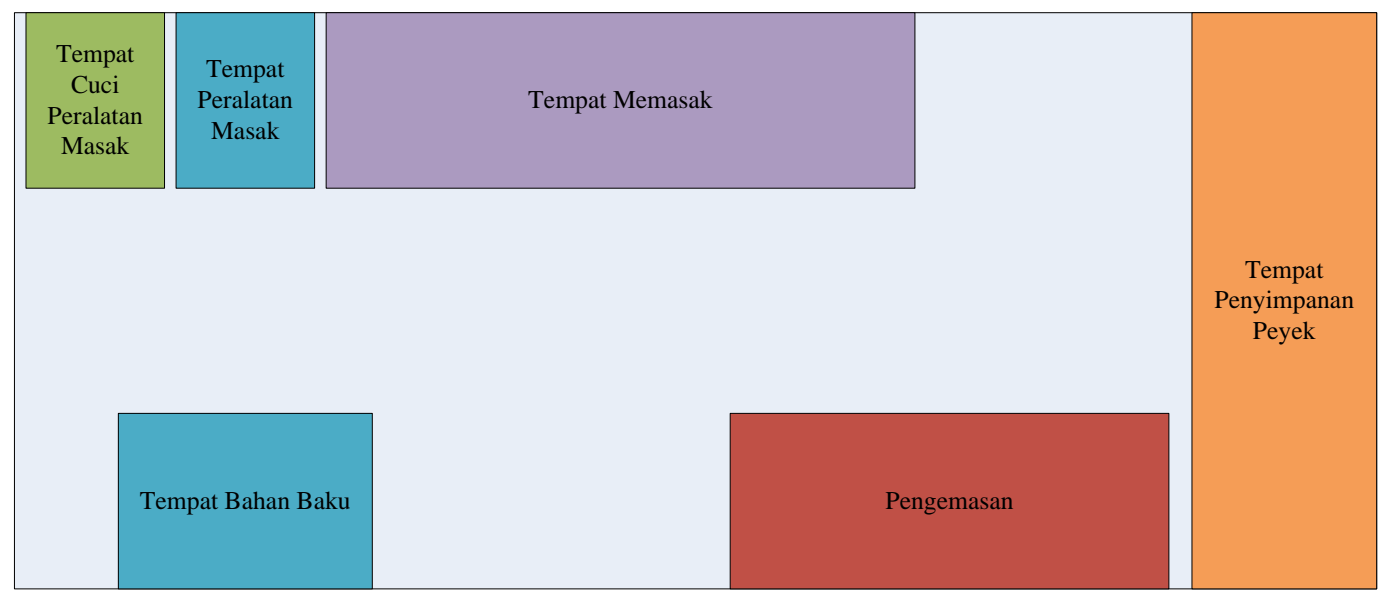

Gambar 8. Rancangan Ulang Tata Letak Fasilitas Produksi Peyek Bu Mul

Berdasarkan analisa ARC dan aliran produksi, tempat bahan baku dirancang di dekat tempat peralatan memasak. Hal ini dikarenakan aliran produksi peyek, dimana langkah awal produksi dimulai dari membuat adonan, dan untuk membuat adonan maka diperlukan wadah dan peralatan memasak lainnya. Sehingga agar karyawan tidak perlu bergerak terlalu jauh makan tempat peralatan memasak dan tempat bahan baku dibuat lebih dekat. Selain itu tempat bahan baku dibuat agak jauh dari tempat memasak agar bahan baku tidak rusak karena panas yang dihasilkan dari kompor pada saat memasak di tempat memasak.

\section{SIMPULAN DAN SARAN}

Kegiatan pengabdian ini telah menghasilkan usulan tata letak fasilitas produksi. Hasil dari kegiatan pengabdian masyarakat di UMKM Peyek Ayu Bu Mul adalah pemilik UMKM Peyek Ayu Bu Mul lebih memahami pentingnya tata letak fasilitas produksi untuk kelancaran produksi peyek. UMKM Peyek Ayu $\mathrm{Bu}$ Mul tertarik untuk menerapkan usulan tata letak fasilitas produksi yang dibuat oleh pengabdi karena dapat meningkatkan kinerja dari produksi peyek. Perancangan tata letak fasilitas produksi dengan mempertimbangkan aliran produksi dan tata letak produksi dapat membantu kelancaran produksi. Pengabdian berikutnya dapat dilanjutkan dengan evaluasi dari penerapan tata letak fasilitas yang sudah diusulkan oleh pengabdi.

\section{DAFTAR PUSTAKA}

Morena Y. dan Siska, M. (2011). Perancangan Ulang Tata Letak Fasilitas Pabrik Pembuatan Batu Bata (Studi Kasus: Kulim, Pekan baru). SNTIKI III, 405 - 413.

Sofyan, D.K., dan Syarifuddin. (2015). Perancangan Ulang Tata Letak Fasilitas Dengan Menggunakan Metode Konvensional Berbasis 5S (Seiri, Seiton, Seiso, Seiketsu Dan Shitsuke). Jurnal Teknovasi, 02, 27 - 41.

Stevenson, J. W. dan Chuong, C. C. (2014). Manajemen Operasi Perspektif Asia (Edisi 9, Buku 1). New York: Mc Graw Hill Education.

Wang, R., Zhao, H., Wu, Y., Wang, Y., Feng, X., dan Liu, M. (2018). An industrial facility layout design method considering energy saving based on surplus rectangle fill algorithm. Energy, 158, 1038 - 1051. 